\title{
Research priority setting in obesity: a systematic review
}

\author{
Halima Iqbal ${ }^{1,2} \cdot$ Rosemary R. C. McEachan ${ }^{2} \cdot$ Jane West $^{2} \cdot$ Melanie Haith-Cooper $^{1}$
}

Received: 23 July 2021 / Accepted: 11 November 2021

(c) The Author(s) 2021

\begin{abstract}
Aim Obesity research priority setting, if conducted to a high standard, can help promote policy-relevant and efficient research. Therefore, there is a need to identify existing research priority setting studies conducted in the topic area of obesity and to determine the extent to which they followed good practice principles for research priority setting.

Method Studies examining research priority setting in obesity were identified through searching the MEDLINE, PBSC, CINAHL, PsycINFO databases and the grey literature. The nine common themes of good practice in research priority setting were used as a methodological framework to evaluate the processes of the included studies. These were context, use of a comprehensive approach, inclusiveness, information gathering, planning for implementation, criteria, methods for deciding on priorities, evaluation and transparency.

Results Thirteen articles reporting research prioritisation exercises conducted in different areas of obesity research were included. All studies reported engaging with various stakeholders such as policy makers, researchers and healthcare professionals. Public involvement was included in six studies. Methods of research prioritisation commonly included both Delphi and nominal group techniques and surveys. None of the 13 studies fulfilled all nine of the good practice criteria for research priority setting, with the most common limitations including not using a comprehensive approach and lack of inclusivity and evaluating on their processes.

Conclusion There is a need for research priority setting studies in obesity to involve the public and to evaluate their exercises to ensure they are of high quality.
\end{abstract}

Keywords obesity $\cdot$ research priority setting $\cdot$ obesity research agenda

\section{Introduction}

Setting priorities for research helps to direct the most effective use of resources, such as research capacity, time and funds, to ensure an optimal health impact (Terry et al. 2018). Research priority setting in health, informed by stakeholders, can assist in the identification of topical and relevant issues, and unresolved questions regarding prevention, diagnosis and treatment of health conditions using a process that is explicit, iterative and inclusive (Rudan et al. 2010). There is currently no consensus on the definition of research priority setting, but there is agreement on a range of activities

Halima Iqbal

h.iqbal23@bradford.ac.uk

1 Faculty of Health Studies, University of Bradford, Richmond Road, Bradford BD7 1DP, UK

2 Bradford Institute for Health Research, Bradford Teaching Hospital NHS Foundation Trust, Bradford, UK that centre on identifying, prioritising and reaching agreement on the research areas or questions deemed important to stakeholders (Tong et al. 2019). In the past, research-funding organisations and researchers developed their own research agendas without consulting key stakeholders (Graham et al. 2020). In recent times, however, there has been a focus on research needing to address questions that have relevance to those very people it intends to help (Dawson et al. 2017). It has been advocated that priority setting processes must also be fair, informed by credible evidence, of high quality and involve a broad range of stakeholders (Nasser et al. 2013; Sibbald et al. 2009; Viergever et al. 2010). Adopting a systematic and transparent approach to the identification of health research priorities can help to ensure that funded research has a public health benefit and make efficient and equitable use of limited resources (Bryant et al. 2014). Developing research agendas with target populations increases the potential for success and is more likely to be well received and relevant to their needs. 


\section{Nine common themes of good practice in research priority setting}

There are currently no published guidelines for reporting priority setting for health research (Tong et al. 2019). In the absence of a gold standard approach, a checklist of nine common themes for good practice in health research prioritisation was developed by Viergever et al. (2010). In developing the checklist, expert consultation was initiated, and a literature review identified several methodological approaches which were combined to draw together a comprehensive outline of common views on what constituted good practice in health research priority setting (Viergever and Roderik 2010). The aim was to facilitate a transparent and comprehensive priority setting via this checklist and accommodate the flexibility required by different contexts.

The nine themes contained within the checklist broadly fall into three different categories: preparatory work, deciding on priorities and after priorities have been set. Each category contains corresponding practices that further identify the goals in each step. There are five related practices within preparatory work, namely context, use of a comprehensive approach (established frameworks providing structured guidance for research prioritisation), inclusiveness, information gathering and planning for implementation. There are two related practices within deciding on priorities, namely criteria and methods for deciding on priorities, and two within after priorities have been set, namely evaluation and transparency. See Table 1 for a detailed description of each theme.

The worldwide prevalence of obesity has significantly increased over the past few decades, leading the trend to be termed a 'global epidemic' by the World Health Organization and a serious threat to public health (World Health Organization 2017). Moreover, obesity is a global issue because it concerns both developed and developing countries (Cassi et al. 2017). The most recent available statistics from 2018/19 show that in England, a significant proportion of adults were overweight or obese, namely $67 \%$ of men and $60 \%$ of women (NHS Digital 2020). Of these, $26 \%$ of men and $29 \%$ of women were obese, and morbid obesity has also increased, from under 1\% in 1993, to 3\% in 2018 (NHS Digital 2020). Excess levels of fat in the body increase the risk of disease (Pollack et al. 2020) and obesity is a major risk factor for developing a range of conditions including cardiovascular disease, type 2 diabetes, muscular disorders, respiratory conditions and a host of psychological problems (Fruh 2017). A recent report by Public Health England highlights that the COVID-19 pandemic has brought to the fore the health crisis caused by overweight and obesity (Public Health England 2020). Both international and national

Table 1 Checklist for health research priority setting adapted from Viergever et al. (2010)

\begin{tabular}{|c|c|}
\hline Theme & Description \\
\hline \multicolumn{2}{|l|}{ Preparatory work } \\
\hline 1 - Context & $\begin{array}{l}1 \text { The resources available for the exercise are reported. } \\
2 \text { The focus of the exercise is clearly stated, i.e. what it is about and who it is for). } \\
3 \text { The underlying values or principles are clear. } \\
4 \text { The health environment in which the process took place is described. } \\
5 \text { The research environment in which the process took place is described. } \\
6 \text { The political environment in which the process took place is described. } \\
7 \text { The economic/financial environment in which the process took place is described. }\end{array}$ \\
\hline 2 - Use of a comprehensive approach & 8 The process of priority setting is described in detail. \\
\hline 3 - Inclusiveness & $\begin{array}{l}9 \text { The participants involved in setting research priorities are described. } \\
10 \text { An appropriate representation of expertise is included. } \\
11 \text { An appropriate representation of the sexes is included. } \\
12 \text { An appropriate representation of regional participation is included. } \\
13 \text { Relevant health sectors and other constituencies are included. }\end{array}$ \\
\hline 4 - Information gathering & 14 The information and sources used to inform the priority setting exercise are referenced. \\
\hline 5 - Planning for implementation & $\begin{array}{l}15 \text { Plans for translation of research priorities are discussed. } \\
16 \text { Who will implement the research priorities and how? }\end{array}$ \\
\hline \multicolumn{2}{|l|}{ Deciding on priorities } \\
\hline 6 - Criteria & 17 Relevant criteria to focus discussion on setting priorities are stated. \\
\hline 7 - Methods for deciding on priorities & 18 Approach for deciding on priorities is described (e.g. consensus or metrics based). \\
\hline \multicolumn{2}{|l|}{ After priorities have been set } \\
\hline 8 - Evaluation & $\begin{array}{l}19 \text { When and how evaluation of the established priorities and the priority setting process } \\
\text { will take place is defined (e.g. multiple sessions). }\end{array}$ \\
\hline 9 -Transparency & 20 Clarity about the approach used exists, i.e. how priorities are set. \\
\hline
\end{tabular}


research has consistently identified obesity as one of the key factors linked with severe outcomes from COVID-19 (Dietz and Santos-Burgoa 2020; Halvatsiotis et al. 2020). The direct annual costs resulting from obesity to the UK National Health Service (NHS) are reportedly estimated to reach $£ 9.7$ billion ( $\$ 13.2$ billion) by 2050 , with wider costs to society predicted to reach just under $£ 50$ billion ( $\$ 67.8$ billion) per year by 2050 (Bradford Metropolitan District Council 2019).

Research is critical to inform prevention and treatment strategies to tackle obesity. Although there is a plethora of research examining the multitude of factors influencing obesity, research budgets are finite. Research priority setting can assist in making the most effective use of budgets by identifying the most relevant research areas according to different stakeholders. There is an emphasis on the need for research priority setting exercises to be explicit in their processes (Tong et al. 2019). Research priority setting guidelines and/or frameworks can help improve future research prioritisation in obesity, thus increasing the value and contribution of research aimed at reducing the obesity levels of populations.

\section{Objectives}

The aim of this systematic review was to identify research priority setting exercises that have been conducted in obesity and to examine whether they had applied good practice principles in health research priority setting.

\section{Methods}

The systematic review followed the standards of the Preferred Reporting Items for Systematic Reviews and MetaAnalyses (PRISMA) statement (Shamseer et al. 2015).

\section{Search strategy and process of study selection}

The search was undertaken between 14-15 November 2020, using four electronic health databases, namely MEDLINE, PBSC, CINAHL and PsychINFO. The following Boolean search term combinations were used:

1. 'research priority setting' [all fields] OR 'research prioritization' [all fields] OR 'research prioritisation' [all fields] OR 'research priorities' [all fields] OR 'research agenda' [all fields]

AND

2. 'obesity' OR 'child obesity' [all fields] OR 'childhood obesity' [all fields] OR 'pediatric obesity' [all fields] OR 'obesity prevention' [all fields] OR 'obesity treatment' [all fields]
3. We searched databases from their inception to November 2020. Only titles and abstracts published in English were included. The principal researcher (HI) independently conducted the article search. Searches in the grey literature included Google Scholar, Cochrane methods priority setting, the James Lind Alliance (a well-established priority-setting partnership method) and reference lists of selected articles to identify eligible papers. The search string 'research priority setting and obesity' was applied to Google Scholar. The first ten pages of Google Scholar were examined for additional articles. All authors contributed and refined the review's search strategy.

\section{Inclusion and exclusion criteria}

The review included any study describing a process of conducting a research prioritisation exercise in obesity. To be included in the review, studies must have outlined participants' characteristics, stated the methods used to obtain research and identified well-established outcomes. International studies were included provided they were written in the English language. Studies were excluded if they did not mention health research, had not described the research prioritisation process or had assessed priorities for practice and policy rather than research (quality indicators). Also excluded were studies that did not focus on obesity research prioritisation.

Across all databases, the search yielded 249 citations, of which 203 remained after duplicates were removed. After the titles and abstracts had been screened, 26 articles underwent full-text screening. Of these publications, 13 studies met our inclusion criteria and were finally included in the analysis. Of the 13 excluded studies, four did not focus mainly on research prioritisation, one was a study protocol, two did not focus on obesity, four were non-research articles and two failed to include the methods and processes. All authors discussed and agreed on the selected papers. References were managed with EndNote X9 for ease. The PRISMA flowchart is displayed in Fig. 1.

\section{Quality assessment tool}

In the absence of a gold standard approach to research priority setting, the checklist of nine common themes for good practice in health research priority setting by Viergever et al. (2010) was used to ascertain whether the research prioritisation exercises in each included study complied with good practice principles in their processes. This checklist has been previously used to evaluate or guide research prioritisation exercises (Doolan-Noble et al. 2019; Iqbal et al. 2021; Mador et al. 2016; Reveiz et al. 2013; Tong et al. 2015;) and has identified weaknesses prevalent in their processes. The checklist was specifically designed for health 


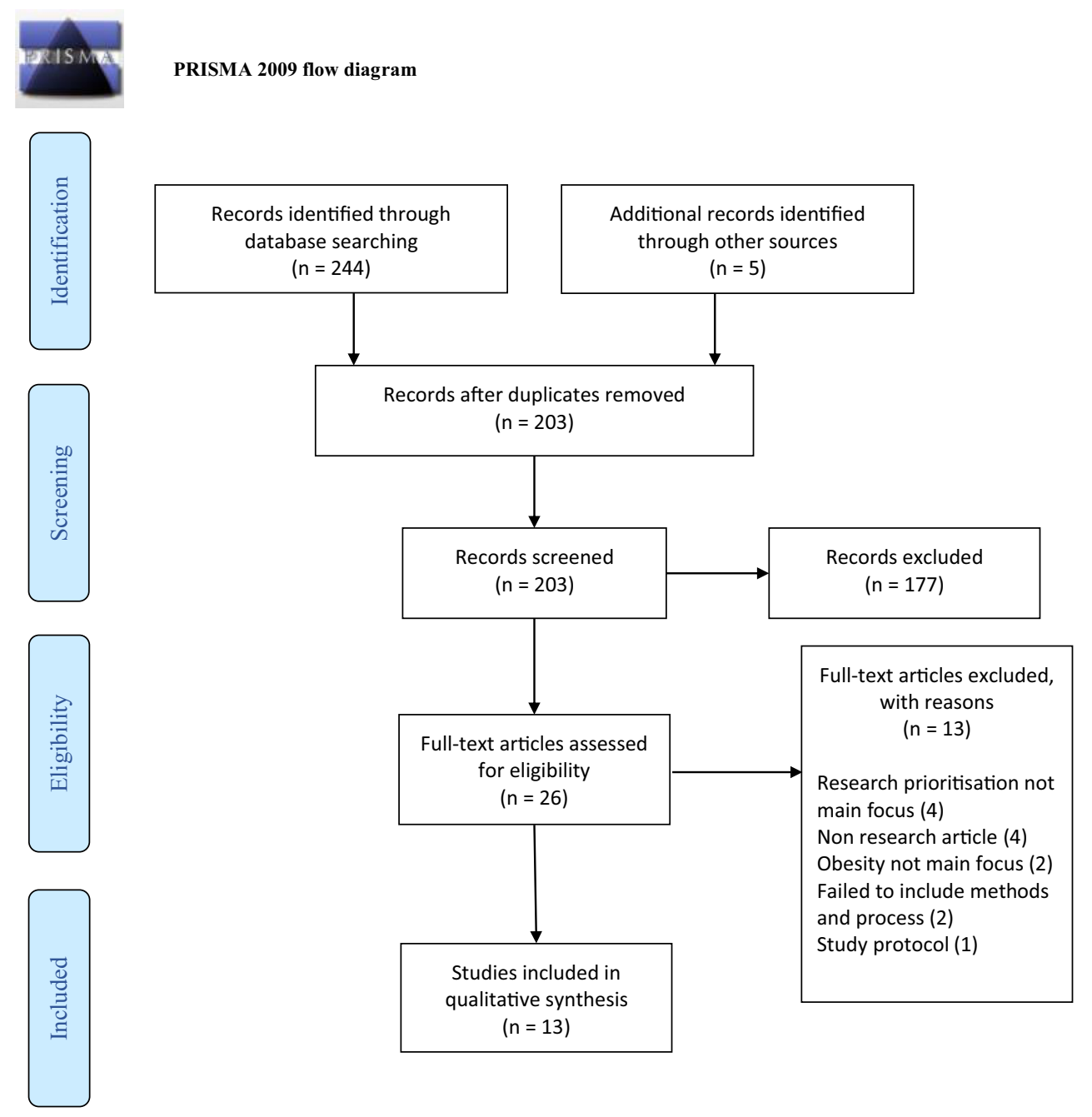

Fig. 1 PRISMA 2009 flow diagram

research priority setting and, as such, can identify issues that may have been otherwise overlooked by traditional quality appraisal tools.

\section{Data synthesis and extraction}

A descriptive synthesis was conducted to outline study characteristics and outcomes, and to determine how many good practice principles each study followed. Studies could score between 0 (demonstrated none of the good practice principles) to 20 (demonstrated all of the good practice principles). One researcher (HI) independently extracted study characteristics, methods and outcomes. The relevant data were inserted into comprehensive data extraction checklist forms developed specifically for the quality synthesis. The quality appraisal criteria were applied by two researchers and resolved through discussion (HI and MC).

\section{Results}

Studies were conducted in research priority setting in the area of obesity for childhood obesity (Botchwey et al. 2018; Byrne et al. 2008; Curtin et al. 2017; Gallagher et al. 2010; Hennessy et al. 2018; McPherson et al. 2016; Ramirez et al. 2011; Taylor et al. 2013; Ward et al. 2013), adult obesity (Hill et al. 2019; Hill et al. 2020; Mama et al. 2014), and obesity more generally (McKinnon et al. 2009). Studies were conducted in the areas of childhood obesity prevention or treatment (Byrne et al. 2008; Gallagher et al. 2010; Hennessy et al. 2018; Taylor et al. 2013), youth physical activity and healthy weight (Botchwey et al. 2018), healthy weight among youth with autism spectrum disorder and other developmental disabilities (Curtin et al. 2017), preconception priorities for maternal obesity prevention (Hill et al. 2019), pregnancy priorities for maternal obesity prevention (Hill et al. 2020), obesity reduction (Mama et al. 2014), 
obesity in children with physical disabilities (McPherson et al. 2016), obesity in Latino children (Ramirez et al. 2011), obesity policy (McKinnon et al. 2009) and obesity prevention in early care and education settings (Ward et al. 2013). The prioritisation exercises were all conducted in high income countries, namely Australia (4), the UK (1) and the US (8).

Seven studies did not include any patient or public involvement in their establishment of research priorities, yet involved a wide range of other stakeholders such as researchers, policy makers/leaders and healthcare professionals (Botchwey et al. 2018; Byrne et al. 2008; Gallagher et al. 2010; Hennessy et al. 2018; McKinnon et al. 2009; Taylor et al. 2013; Ward et al. 2013). One study solely involved the public in identifying priorities (Mama et al. 2014) and the remaining five studies involved the public alongside other stakeholders (Curtin et al. 2017; Hill et al. 2019; Hill et al. 2020; McPherson et al. 2016; Ramirez et al. 2011). Frequently cited methods used to identify priorities were surveys, Delphi techniques and the nominal group technique.

The main outcome of the studies was the generation of research priorities relevant to the topic and scope of each study. The priorities were described as prioritised research ideas/gaps/areas, prioritised lists, research priorities and prioritised themes. All 13 studies are displayed in Table 2 below.

When matched against the checklist of good practice principles in research priority setting as defined by Viergever et al. (2010), none of the studies adhered to all the principles outlined in the checklist (see Table 3).

\section{Summary of the comprehensiveness of studies in reporting good practice principles}

\section{Theme 1: Context}

The focus of the exercise was made clear in all studies, as were the underlying values and principles of each study. These included the need to engage the community in identifying obesity research priorities (Mama et al. 2014), or to foster collaboration amongst interdisciplinary research experts in the field of healthy weight, prevention of weight gain and maintenance of healthy weight (Gallagher et al. 2010; Hennessy et al. 2018; Taylor et al. 2013), or to develop a research agenda leveraging the collective expertise of a range of stakeholders (McPherson et al. 2016). However, the resources used for the exercises were made explicit in very few studies. Where information was provided, these included the use of materials used during the exercise such as cards to write knowledge gaps on (McPherson et al. 2016), flipcharts and numbered stickers for ranking (Hennessy et al. 2018), the use of audio-recorders
(Mama et al. 2014) and the use of facilitators (Gallagher et al. 2010; Hennessy et al. 2018; Hill et al. 2020; Hill et al. 2019; McKinnon et al. 2009; McPherson et al. 2016) and project staff members to take notes and capture details around the issues raised (Ward et al. 2013), as well as the use of a statistician, data analyst and administrative support staff (Curtin et al. 2017). In one study, the use of a transcription service was disclosed (Mama et al. 2014). The economic/financial and political environment in which the prioritisation exercise took place was not disclosed in any of the studies.

\section{Theme 2: Use of a comprehensive approach}

None of the studies reported the use of established, structured, step-by-step frameworks specifically designed for research priority setting to guide their prioritisation processes, such as the James Lind Alliance (JLA) methodology (JLA 2020), the Essential National Health Research (ENHR) strategy (COHRED 2009), the Combined Approach Matrix (CAM) (Ghaffar 2009) and the Child Health and Nutrition Research Initiative (CHNRI) (Rudan 2016). None of the studies developed their own frameworks to guide their exercises.

\section{Theme 3: Inclusiveness}

Across prioritisation exercises, participants comprised a diverse range of stakeholders. Samples were inclusive of health service managers, medical practitioners, healthcare practitioners, academics, interdisciplinary researchers, dietitians, scientists, government agencies, policy leaders and experts in the field of child obesity more generally. Two studies solely involved researchers in the process (Gallagher et al. 2010; Taylor et al. 2013). Public involvement in the exercise was made explicit in six studies only (Curtin et al. 2017; Hill et al. 2020; Hill et al. 2019; Mama et al. 2014; McPherson et al. 2016; Ramirez et al. 2011). Although all studies discussed participant characteristics, some were more detailed in their descriptions by disclosing the sex of participants (Hennessy et al. 2018; Mama et al. 2014; Ramirez et al. 2011), with women overwhelmingly outnumbering men in two studies (Hennessy et al. 2018; Ramirez et al. 2011). An appropriate representation of regional participation was included in most studies that did not involve the public, as well as the incorporation of relevant sectors.

\section{Theme 4: Information gathering}

In some studies, a core planning group or committee suggested initial priorities to direct the process (Gallagher et al. 2010; Ramirez et al. 2011; Ward et al. 2013), or 


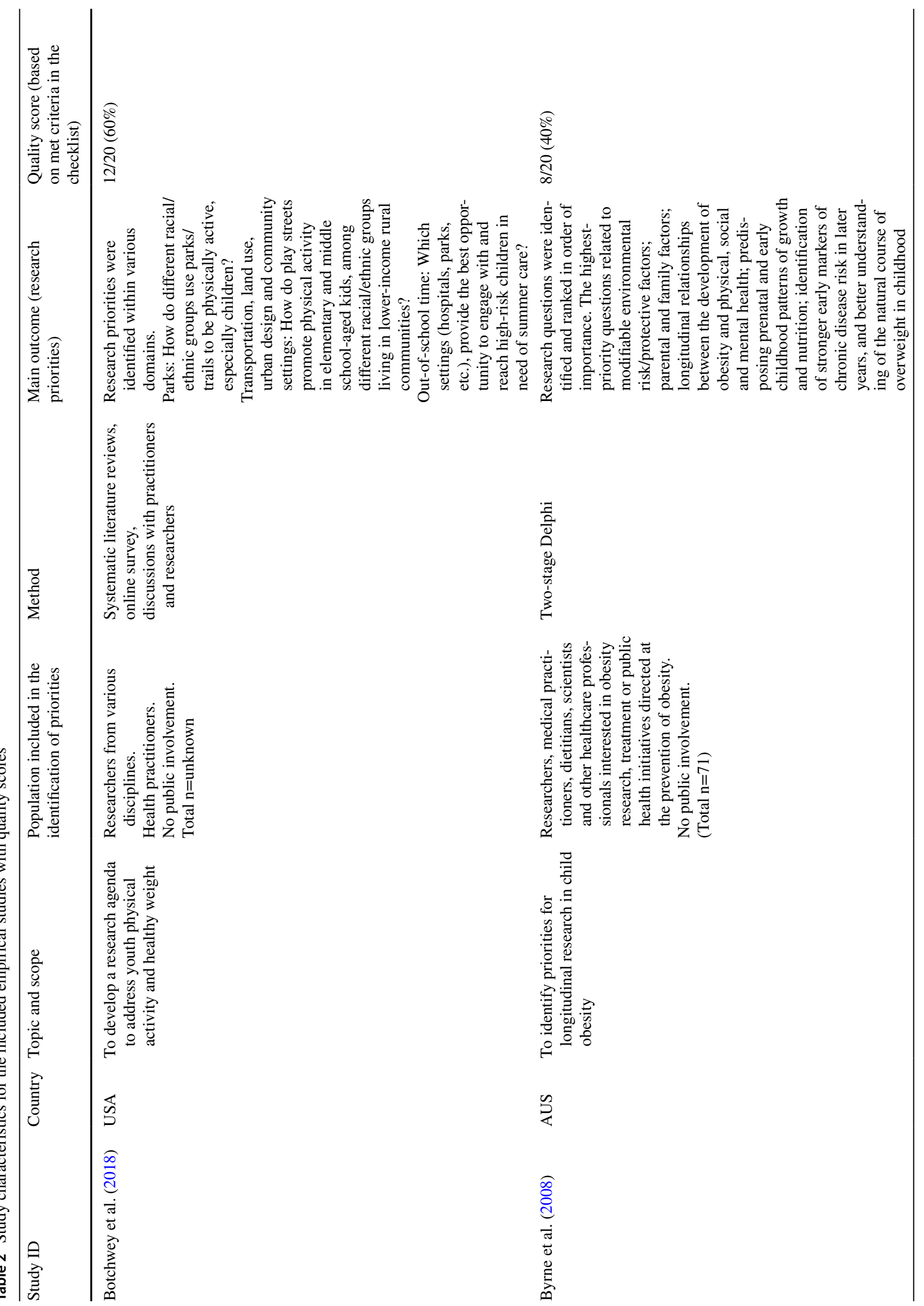




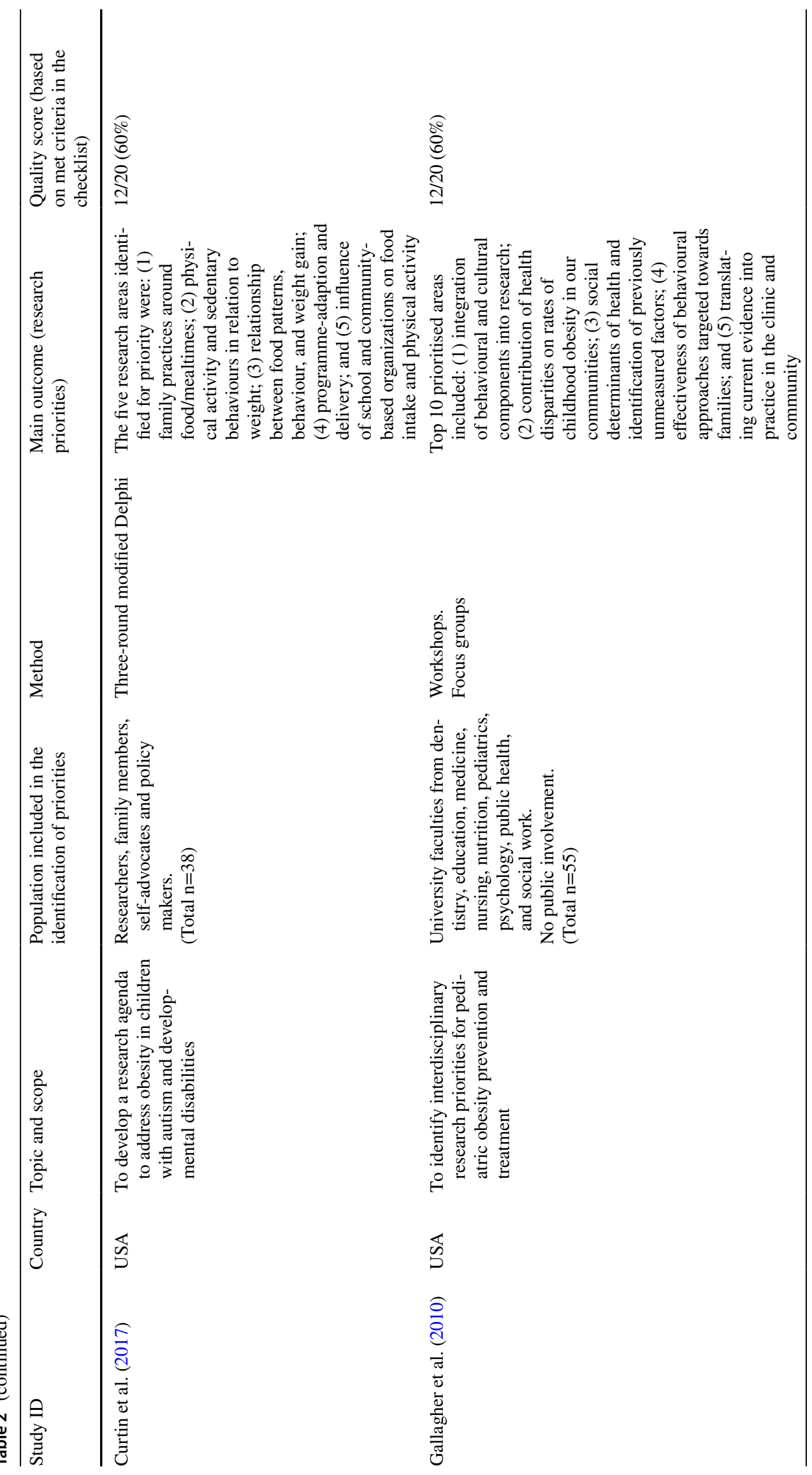




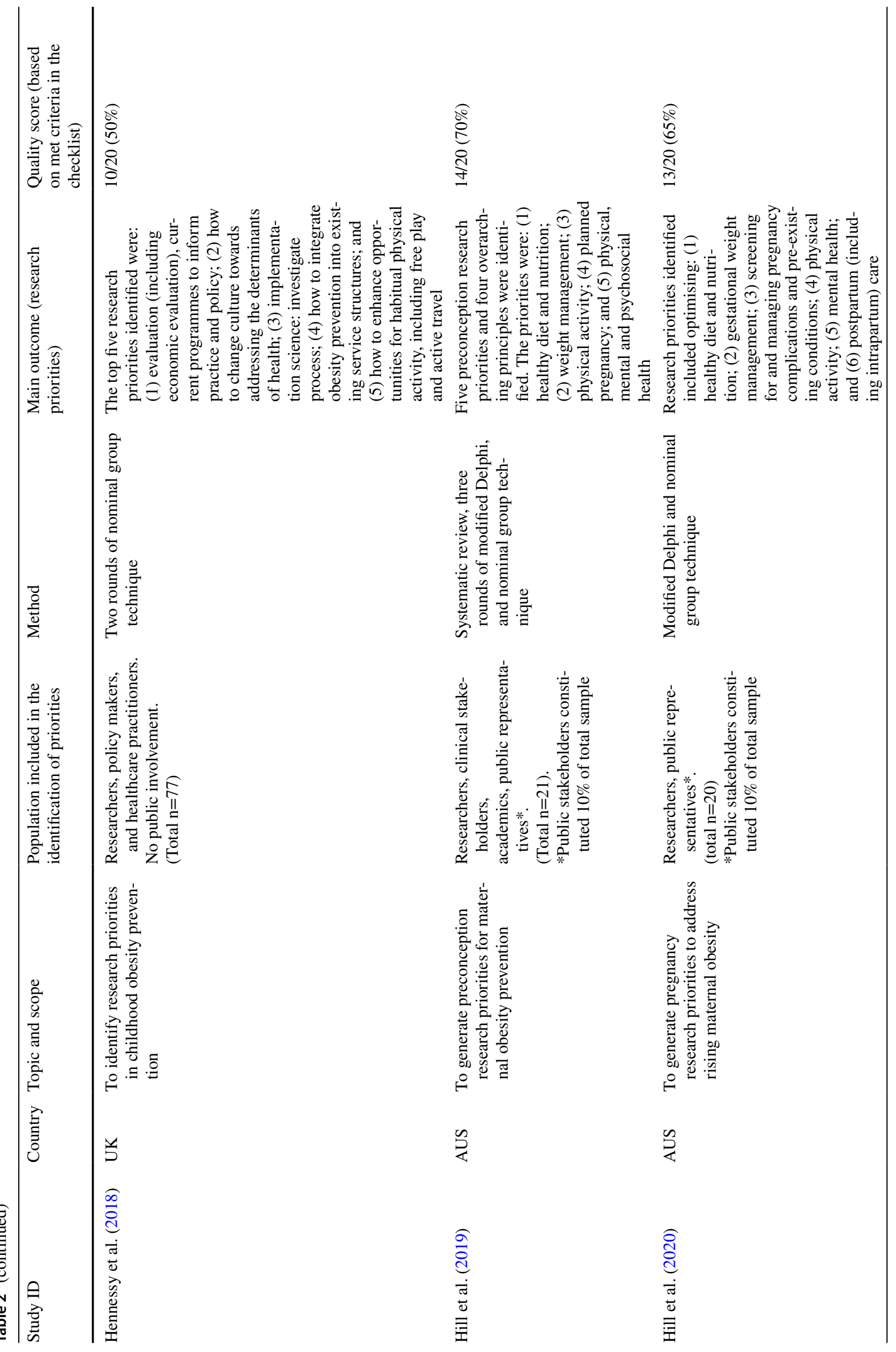




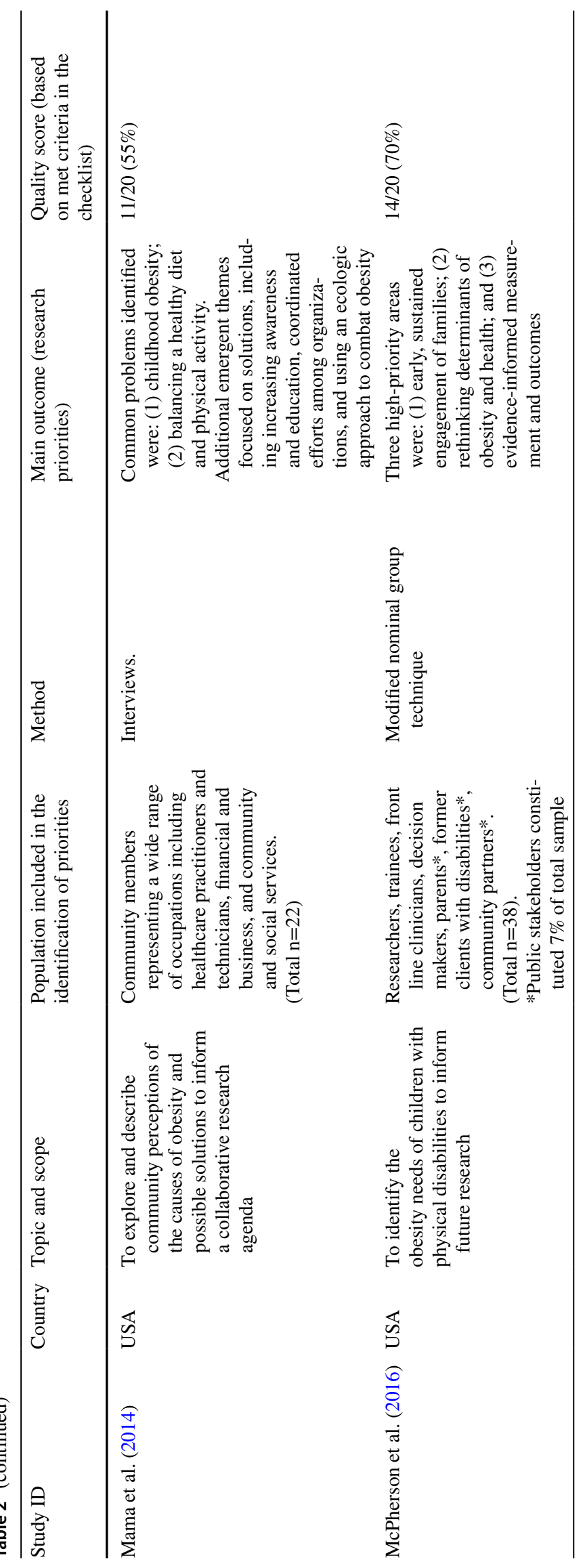




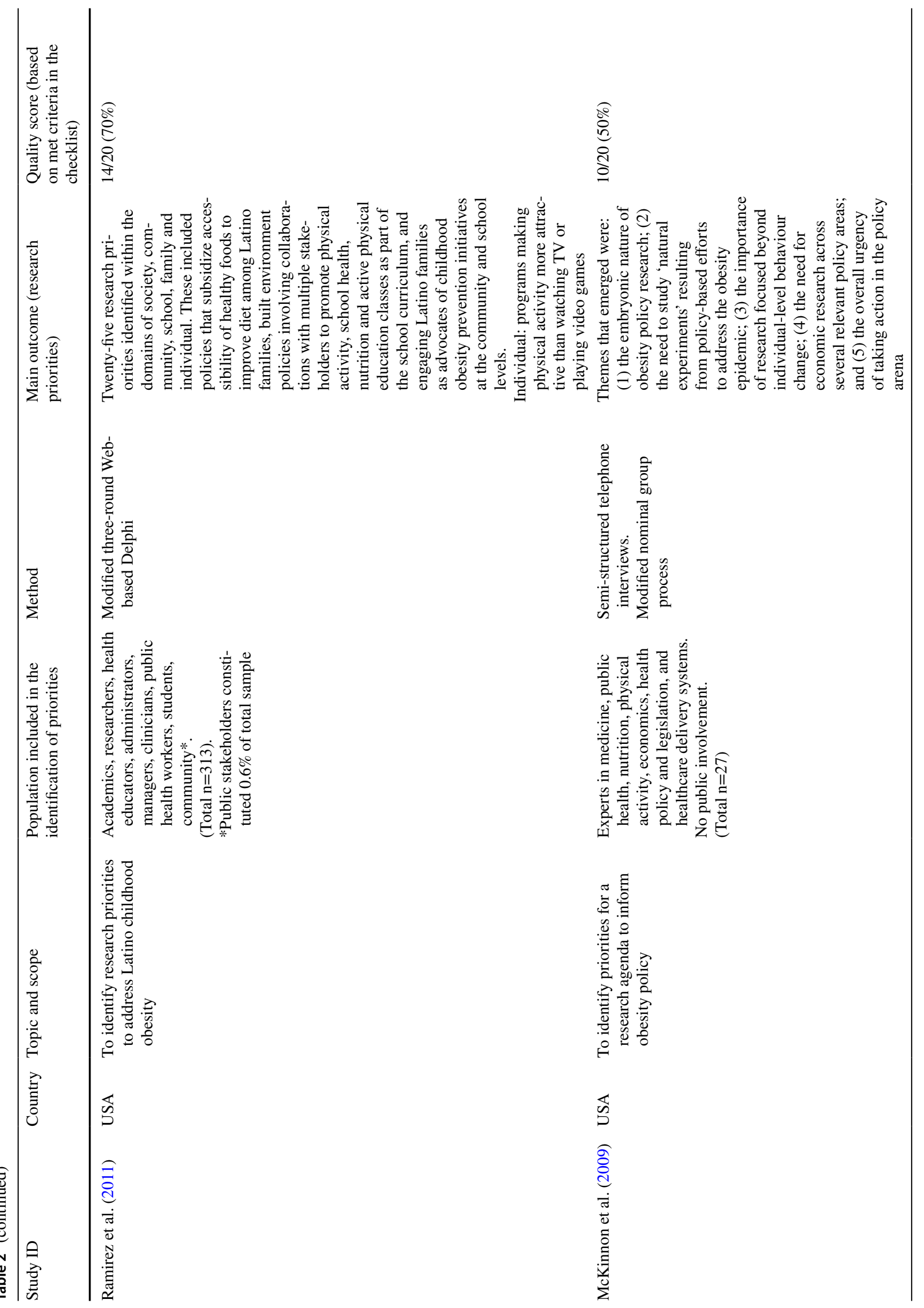




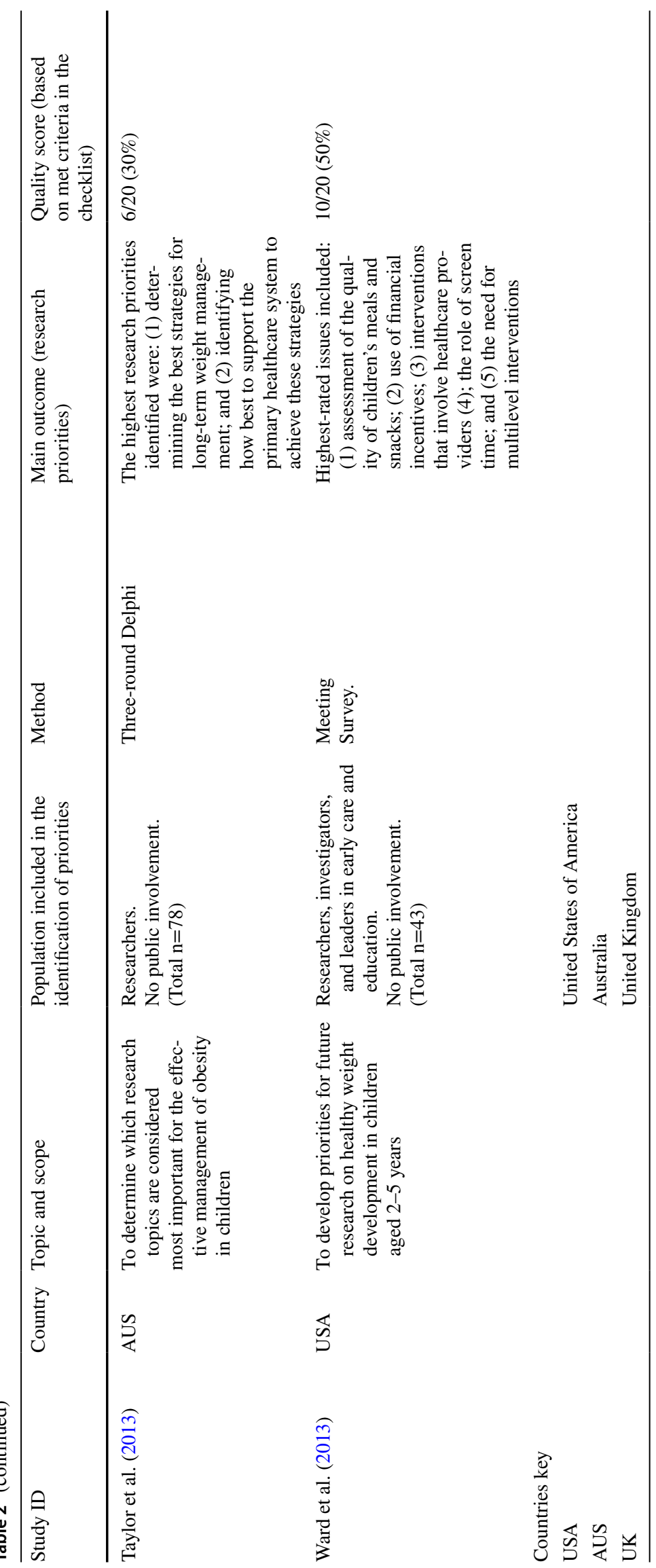


Table 3 Appraisal of comprehensiveness of reporting

\begin{tabular}{l}
\hline Item $\quad \begin{array}{l}\text { Studies that fulfilled the principles outlined in the checklist } \\
\text { Total studies } \\
\text { (out of } a \text { total } \\
\text { of 13) }\end{array}$ \\
\hline
\end{tabular}

Context

1 - The resources available for the exercise are reported

2 - The focus of the exercise is clearly stated, i.e. what it is about and who it was for

3 - The underlying values or principles are clear

4 - The health environment in which the process took place is described

5 - The research environment in which the process took place is described

6 - The political environment in which the process took place is described

7 - The economic/financial environment in which the process took place is described

Use of a comprehensive approach

8 - The process of priority setting is described in detail

Inclusiveness

9 - The participants involved in setting research priorities are described

\section{0 - An appropriate representation of expertise is included}

11 - An appropriate representation of the sexes is included

12 - An appropriate representation of regional participation is included

\section{3 - Relevant health sectors and other constituencies are included}

Information gathering

14 - The information and sources used to inform the priority setting exercise are referenced
Curtin et al. (2017); Gallagher et al. (2010); Hennessy et al. (2018); Hill et al. (2020); Hill et al. (2019); Mama et al.

(2014); McKinnon et al. (2009); McPherson et al. (2016); Ward et al. (2013)

Botchwey et al. (2018); Byrne et al. (2008); Curtin et al. (2017); Gallagher et al. (2010); Hennessy et al. (2018); Hill et al. (2020); Hill et al. (2019); Mama et al. (2014); McKinnon et al. (2009); McPherson et al. (2016); Taylor et al. (2013); Ramirez et al. (2011); Ward et al. (2013)

Botchwey et al. (2018); Byrne et al. (2008); Curtin et al. (2017); Gallagher et al. (2010); Hennessy et al. (2018); Hill et al. (2020); Hill et al. (2019); Mama et al. (2014); McKinnon et al. (2009); McPherson et al. (2016); Ramirez et al. (2011); Taylor et al. (2013); Ward et al. (2013)

Botchwey et al. (2018); Curtin et al. (2017); Gallagher et al. (2010); Hennessy et al. (2018); Hill et al. (2020); Hill et al. (2019); Mama et al. (2014); McKinnon et al. (2009); McPherson et al. (2016); Ramirez et al. (2011); Ward et al. (2013)

Byrne et al. (2008); Curtin et al. (2017); Gallagher et al. (2010); Hennessy et al. (2018); Hill et al. (2020); Hill et al. (2019); Mama et al. (2014); McPherson et al. (2016); McKinnon et al. (2009); Ramirez et al. (2011); Taylor et al. (2013); Ward et al. (2013)

0

Botchwey et al. (2018); Byrne et al. (2008); Curtin et al. (2017); Gallagher et al. (2010); Hennessy et al. (2018); Hill et al. (2020); Hill et al. (2019); Mama et al. (2014); McKinnon et al. (2009); McPherson et al. (2016); Ramirez et al. (2011); Taylor et al. (2013); Ward et al. (2013)

Curtin et al. (2017); Hill et al. (2020); Hill et al. (2019); Mama 6 et al. (2014); McPherson et al. (2016); Ramirez et al. (2011)

Mama et al. (2014) 1

Botchwey et al. (2018); Byrne et al. (2008); Curtin et al. 10 (2017); Gallagher et al. (2010); Hennessy et al. (2018); Hill et al. (2020); Hill et al. (2019); Mama et al. (2014); McPherson et al. (2016); Ramirez et al. (2011)

Botchwey et al. (2018); Byrne et al. (2008); Curtin et al. (2017); Hill et al. (2019); McKinnon et al. (2009); McPherson et al. (2016); Ramirez et al. (2011); Ward et al. (2013)

Botchwey et al. (2018); Byrne et al. (2008); Curtin et al. (2017); Gallagher et al. (2010); Hennessy et al. (2018); Hill et al. (2020); Hill et al. (2019); Mama et al. (2014); McKinnon et al. (2009); McPherson et al. (2016); Ramirez et al. (2011); Taylor et al. (2013); Ward et al. (2013) 
Table 3 (continued)

\begin{tabular}{|c|c|c|}
\hline Item & Studies that fulfilled the principles outlined in the checklist & $\begin{array}{l}\text { Total studies } \\
\text { (out of a total } \\
\text { of } 13 \text { ) }\end{array}$ \\
\hline \multicolumn{3}{|l|}{ Planning for implementation } \\
\hline 15 - Plans for translation of research priorities are discussed & $\begin{array}{l}\text { Botchwey et al. (2018); Gallagher et al. (2010); Hill et al. } \\
\text { (2020); Hill et al. (2019); McPherson et al. (2016); Ramirez } \\
\text { et al. (2011) }\end{array}$ & 6 \\
\hline 16 - Who has implemented the research priorities and how? & $\begin{array}{l}\text { Botchwey et al. (2018); Gallagher et al. (2010); Hill et al. } \\
\text { (2020); Ramirez et al. (2011) }\end{array}$ & 4 \\
\hline \multicolumn{3}{|l|}{ Criteria } \\
\hline $\begin{array}{l}17 \text { - Relevant criteria to focus discussion on setting priorities } \\
\text { are stated }\end{array}$ & $\begin{array}{l}\text { Botchwey et al. (2018); Hill et al. (2020); Hill et al. (2019); } \\
\text { McKinnon et al. (2009); McPherson et al. (2016); Ramirez } \\
\text { et al. (2011) }\end{array}$ & 6 \\
\hline \multicolumn{3}{|l|}{ Methods for deciding on priorities } \\
\hline $\begin{array}{l}18 \text { - Approach for deciding on priorities is described (e.g. } \\
\text { consensus or metrics based) }\end{array}$ & $\begin{array}{l}\text { Botchwey et al. (2018); Byrne et al. (2008); Curtin et al. } \\
\text { (2017); Gallagher et al. (2010); Hennessy et al. (2018); Hill } \\
\text { et al. (2020); Hill et al. (2019); Mama et al. (2014); McKin- } \\
\text { non et al. (2009); McPherson et al. (2016); Ramirez et al. } \\
\text { (2011); Taylor et al. (2013); Ward et al. (2013) }\end{array}$ & 13 \\
\hline \multicolumn{3}{|l|}{ Evaluation } \\
\hline $\begin{array}{l}19 \text { - When and how evaluation of the established priorities and } \\
\text { the priority setting process will take place is defined (e.g. } \\
\text { multiple sessions) }\end{array}$ & 0 & 0 \\
\hline \multicolumn{3}{|l|}{ Transparency } \\
\hline $\begin{array}{l}20 \text { - Clarity about the approach used exists, i.e. how priorities } \\
\text { are set }\end{array}$ & $\begin{array}{l}\text { Botchwey et al. (2018); Byrne et al. (2008); Curtin et al. } \\
\text { (2017); Gallagher et al. (2010); Hennessy et al. (2018); Hill } \\
\text { et al. (2020); Hill et al. (2019); Mama et al. (2014); McPher- } \\
\text { son et al. (2016); Ramirez et al. (2011); Taylor et al. (2013); } \\
\text { Ward et al. (2013) }\end{array}$ & 12 \\
\hline
\end{tabular}

researchers identified the initial areas and other stakeholders prioritised the selected areas (Botchwey et al. 2018; Byrne et al. 2008). The use of technical data was reported in most studies. These included reviews of guidelines and recommendations (Hill et al. 2020; Hill et al. 2019), as well as literature searches, reports and systematic reviews (Botchwey et al. 2018; Hill et al. 2020; Ramirez et al. 2011). Surveys were conducted to obtain broad input on the selected topic areas (Botchwey et al. 2018; Byrne et al. 2008; Curtin et al. 2017), as were questionnaires (Ramirez et al. 2011; Taylor et al. 2013). Workshops (Gallagher et al. 2010; Hennessy et al. 2018; Hill et al. 2019; Hill et al. 2020; McPherson et al. 2016), group meetings (Curtin et al. 2017; McPherson et al. 2016; Ward et al. 2013) and brainstorming sessions were also reported as a means of generating information (Curtin et al. 2017), as well as presentations (McPherson et al. 2016; Ward et al. 2013).

\section{Theme 5: Planning for implementation}

Most of the studies did not report their plans for implementing identified priorities. Several community projects were established from two research priority setting studies
(Gallagher et al. 2010; Ramirez et al. 2011). Plans for implementing pilot studies were established from a research agenda (Ramirez et al. 2011). Ongoing activities influenced by the identified priorities were reported in two studies (Hill et al. 2019; Hill et al. 2020). The research agenda shaped four initial projects in another study (Botchwey et al. 2018) and finally, one study secured a large team grant to address some items on their research agenda (McPherson et al. 2016).

\section{Theme 6: Criteria}

Criteria to focus discussion on research priorities were mentioned in six studies (Botchwey et al. 2018; Hill et al. 2020; Hill et al. 2019; McKinnon et al. 2009; McPherson et al. 2016; Ramirez et al. 2011). Cited criterion included research priorities that had the greatest long-term impact, and what would have the most immediate impact (Botchwey et al. 2018), prevalence or burden attributable to the proposed problem (Hill et al. 2019), provision, potential and proposed transformation attributable to the problem (Hill et al. 2020), preventative effect with respect to obesity development, and implementation feasibility (Hill et al. 2020), and 
the most appropriate and feasible methods for initiating research efforts (McPherson et al. 2016).

\section{Theme 7: Methods for deciding on priorities}

Studies either adopted a metrics approach (Botchwey et al. 2018; Byrne et al. 2008; Curtin et al. 2017; Gallagher et al. 2010; Taylor et al. 2013; Ward et al. 2013), a consensus approach (McPherson et al. 2016; Ramirez et al. 2011) or a combination of both (Hennessy et al. 2018; Hill et al. 2019; Hill et al. 2020). Likert scales were utilised in one study for ranking priorities (Ramirez et al. 2011), as were numbered stickers (Hennessy et al. 2018). The Delphi method was the most used method for deciding on priorities, both in its original form (Byrne et al. 2008; Ramirez et al. 2011; Taylor et al. 2013) and adapted versions, followed by the nominal group technique (Hennessy et al. 2018). In two studies, the Delphi technique was combined with the nominal group technique (Hill et al. 2019; Hill et al. 2020). One study used a modified nominal group technique to determine priorities (McKinnon et al. 2009). Another study did not use ranking and/or consensus to determine priorities, and instead searched for themes in the data and described these as the priorities (Mama et al. 2014).

\section{Theme 8: Evaluation}

There were no reported plans to update the priorities. One study mentioned that the research agenda would be reviewed, re-evaluated and refined (Curtin et al. 2017).

\section{Theme 9: Transparency}

Most of the studies were explicit in their priority setting processes, despite not using a well-established framework, although some were more transparent than others (Gallagher et al. 2010; Hennessy et al. 2018; Hill et al. 2020; Hill et al. 2019; Ramirez et al. 2011). The majority of studies outlined how the priorities were set. In most cases, it was clear which stakeholders identified initial topics, which stakeholders added generated additional input and who exactly prioritised.

Some studies also highlighted the limitations of their prioritisation exercise, such as acknowledging the lack of public involvement altogether (Hennessy et al. 2018), the possibility of unequal representation of disciplines (Hill et al. 2019; Hill et al. 2020), the lack of participation in person by children or youth (McPherson et al. 2016) and the lack of men that participated (Hennessy et al. 2018). Further highlighted limitations were around the issue of generalisability. This included the small sample size (Taylor et al. 2013), method of sample recruiting (Mama et al. 2014) and the possibility of selection bias due to the participants not being randomly selected (Ramirez et al. 2011). Other challenges were also highlighted, such as issues encountered in achieving consensus during the prioritisation phases (Hennessy et al. 2018), and the steps taken to reduce potential limitations when using the nominal group technique (Hennessy et al. 2018; Hill et al. 2019). One study reported pilot testing the questionnaire used to elicit priorities utilising a survey instrument, and subsequently revising it for improvement (Ramirez et al. 2011).

\section{Discussion}

This review provides an assessment of research priority setting initiatives in the area of obesity. Most of the prioritisation exercises focussed on obesity topics including causes, prevention and management. Of the 13 identified studies, ten concentrated on child obesity, three on adult obesity and one focussed on obesity more generally. The application of a checklist of good practice principles in research priority setting identified the strengths and weaknesses inherent in each study. None of the studies fulfilled all the good practice principles as outlined by the checklist. It is clear that more effort needs to be made in studies examining obesity research priority setting to ensure that their processes are of a high quality. It is important to note however, that two studies (Byrne et al. 2008; McKinnon et al. 2009) were conducted before the checklist of nine common themes of good practice was published in 2010. In addition, literature advocating the need for research priority setting to be fair, legitimate, informed by credible evidence, include a wide range of stakeholders and be transparent, has only more recently been strongly advocated (Bhaumik et al. 2015; Nasser et al. 2013; Tong et al. 2019; Viergever et al. 2010) which may be as a result of the increase in research prioritisation exercises in the past two decades. Our findings suggest that the greatest limitations of studies when applied to the checklist of good practice concerned the criteria use of comprehensive approach, inclusiveness and evaluation.

None of the studies used comprehensive well-established research priority setting frameworks such as the JLA methodology, the ENHR strategy, the CAM and the CHNRI initiative. These established schemata were all developed before the studies were undertaken and provide step-by-step guidance for the entire process, while covering many of the points on the checklist (Viergever et al. 2010). It is argued by Viergever et al. (2010) that the use of these structurally welldefined tools and methods should at least be considered, and that they will gradually replace commonly used methods such as the Delphi method (Yoshida 2016), which was a frequently used method used to establish obesity priorities in the identified studies. 
It is concerning that only six of the 13 studies in this review involved the public as stakeholders and even then, the public were significantly underrepresented in the sample (Hill et al. 2020; Hill et al. 2019; McPherson et al. 2016; Ramirez et al. 2011), with another study not making clear how many public stakeholders were involved in the process (Curtin et al. 2017). Interestingly, of the seven studies that scored the highest in this review, six of them involved the public in the generation of priorities. It is well established in the literature that community engagement in research priority setting is crucial for establishing research questions that are relevant to them. Previous studies have demonstrated that the research priorities of other stakeholders do not align with those of the public (Brady et al. 2020; Manikam et al. 2017; Owens et al. 2008; Tallon et al. 2000; Voigt et al. 2010). A 2014 report systematically reviewed research priority setting studies from the period 1966 to 2014 and found that in the 91 studies, researcher and government involvement was strong, yet involvement of other key stakeholders was limited (McGregor et al. 2014). To ensure the incorporation of public and patients in the process, guidelines are available such as the Guidance for Reporting Involvement of Patients and the Public (GRIPP) checklist (Staniszewska et al. 2017), which was developed to aid in improving the quality, consistency and transparency of reporting the inclusion of patients and the public in research. The checklist offers a comprehensive list of issues that require consideration when reporting activities in relation to public and patient involvement. It must be noted, however, that it fails to offer information on how the public and patient contributors are to be recruited (Dawson et al. 2017). Additionally, it does not offer explicit consideration for representing the diversity of the population relevant to the topic area (Dawson et al. 2017). It is unclear in the current review whether public stakeholders were representative of the community at large, i.e. whether there was inclusion of Black and minority ethnic stakeholders in the samples. In addition to ensuring the inclusion of the public in research priority setting exercises, it is recommended that key characteristics of the sample are recorded and reported so that issues in relation to inclusion and diversity can be understood.

With regard to evaluation, a small number of studies in this review described strategies for the implementation of identified priorities, yet none measured the impact of the prioritisation. This can be done, for example, by performing an impact assessment reviewing the research performed (Viergever and Roderik 2010). The authors of a 2014 report (McGregor et al. 2014) argued that many of the exercises failed to translate the result of the prioritisation process into implementation of projects. It was further highlighted that the exercises were rarely repeated due to the lack of follow-up. The authors of the current review would strongly endorse the use of good practice guidelines, such as the one used to critically appraise the studies in this review, or the Reporting Guideline for Priority Setting of Health Research (REPRISE) by Tong et al. (2019).

\section{Conclusion}

In summary, one can say that while research priority setting studies in the topic area of obesity do exist, they vary in scope and in quality. Although a wide range of stakeholders were involved in the prioritisation processes, public involvement was either non-existent or limited. The use of a comprehensive approach in research priority setting and/or adherence to good practice guidelines could enrich obesity priority setting processes to ensure the identified obesity priorities are relevant, transparent and can assist in implementation efforts. It is imperative that the public be involved in the obesity research priority setting process, resulting in research agendas that have incorporated their unmet needs. This can improve the relevance and legitimacy of research and ultimately achieve better health outcomes in obesity.

Authors' contributions Conceptualisation: Halima Iqbal, Melanie Haith-Cooper, Rosie McEachan, Jane West; Methodology: Halima Iqbal; Formal analysis and investigation: Halima Iqbal, Melanie Haith-Cooper; Writing - original draft preparation: Halima Iqbal; Writing - review and editing: Halima Iqbal, Melanie Haith-Cooper, Rosie McEachan, Jane West; Resources: Halima Iqbal; Supervision: Halima Iqbal

Funding This work was supported by the National Institute for Health Research (NIHR) under its Applied Research Collaboration (ARC) Yorkshire and Humber in the form of Ph.D. funding to HI [NIHR200166], the UK Prevention Research Partnership (UKPRP) in the form of funding to JW and RM [MR/S037527/1], the NIHR Clinical Research Network in the form of funding to JW, and the NIHR ARC Yorkshire and Humber in the form of funding to RM

Availability of data and material DOI's are cited in the reference list

\section{Declarations}

Conflicts of interest The authors declare they have no financial or nonfinancial interests to disclose.

Ethics approval This is a systematic review. The University of Bradford Ethics Committee has confirmed that no ethical approval is required

Consent to participate Not applicable

Consent for publication Not applicable

Code availability Not applicable

Open Access This article is licensed under a Creative Commons Attribution 4.0 International License, which permits use, sharing, 
adaptation, distribution and reproduction in any medium or format, as long as you give appropriate credit to the original author(s) and the source, provide a link to the Creative Commons licence, and indicate if changes were made. The images or other third party material in this article are included in the article's Creative Commons licence, unless indicated otherwise in a credit line to the material. If material is not included in the article's Creative Commons licence and your intended use is not permitted by statutory regulation or exceeds the permitted use, you will need to obtain permission directly from the copyright holder. To view a copy of this licence, visit http://creativecommons. org/licenses/by/4.0/.

\section{References}

Bradford District Metropolitan Council) (BDMC) (2019) Living well: overweight and obesity. Available online at: https://jsna.bradf ord.gov.uk/documents/People\%20are\%20living\%20their\%20liv es $\% 20$ well $\% 20$ and $\% 20$ ageing $\% 20$ well $/ 4.2 \% 20$ LIfestyle $\% 20 \mathrm{Fac}$ tors/Overweight\%20and\%20Obesity.pdf. Accessed 16 Nov 2020

Bhaumik S, Rana S, Karimkhani C, Welch V, Armstrong R, Pottie K, Dellavalle R, Dhakal P, Oliver S, Francis DK, Nasser M, Crowe S, Aksut B, Amico RD (2015) Ethics and equity in research priority-setting: stakeholder engagement and the needs of disadvantaged groups. Indian J Med Ethics 12:110-3. https://doi.org/10.20529/IJME.2015.030

Botchwey N, Floyd MF, Pollack Porter K, Cutter CL, Spoon C, Schmidt TL, Conway TL, Hipp JA, Kim AJ, Umstattd Meyer MR, Walker AL, Kauth TJ, Sallis JF (2018) Policy and PracticeRelevant Youth Physical Activity Research Center Agenda. J Phys Act Health 15:626-634. https://doi.org/10.1123/jpah.2017-0327

Brady PC, Horne AW, Saunders PTK, Thomas AM, Missmer SA, Farland LV (2020) Research priorities for endometriosis differ among patients, clinicians, and researchers. Am J Obstet Gynecol 222:630-632. https://doi.org/10.1016/j.ajog.2020.02.047

Bryant J, Sanson-Fisher R, Walsh J, Stewart J (2014) Health research priority setting in selected high income countries: a narrative review of methods used and recommendations for future practice. Cost Eff Resour 12:23

Byrne S, Wake M, Blumberg D, Dibley M (2008) Identifying priority areas for longitudinal research in childhood obesity: Delphi technique survey. Int J Pediatr Obes 3:120-122. https://doi.org/ 10.1080/17477160701830796

Cassi L, Lahattel A, Rafols I, Sauther P, De Turckheim É (2017) Improving fitness: Mapping research priorities against societal needs on obesity. J Informetr 11:1095-1113. https://doi.org/10. 1016/j.joi.2017.09.010

COHRED (2009) A manual for research priority setting using the ENHR strategy. Available online at: http://www.cohred.org/ downloads/578.pdf. Accessed 16 Nov 2020

Curtin C, Must A, Phillips S, Bandini L (2017) The healthy weight research network: a research agenda to promote healthy weight among youth with autism spectrum disorder and other developmental disabilities. Pediatr Obes 12:e6-e9. https://doi.org/ 10.1111/ijpo.12109

Dawson S, Campbell SM, Giles SJ, Morris RL, Cheraghi-sohi S (2017) Black and minority ethnic group involvement in health and social care research: a systematic review. Health Expect 21:3-22. https://doi.org/10.1111/hex.12597

Dietz W, Santos-burgoa C (2020) Obesity and its implications for COVID-19 mortality. Obesity 28:1005. https://doi.org/10.1002/ oby. 22818

Doolan-Noble F, Mehta P, Waters D, Baxter GD (2019) Supporting ageing well research: Findings from a research priority setting exercise. Australas J Ageing 38:136-143. https://doi.org/10. 1111/ajag.12615

Fruh SM (2017) Obesity: risk factors, complications, and strategies for sustainable long-term weight management. J Am Ass Nurse Pract 29:S3-S14. https://doi.org/10.1002/2327-6924.12510

Gallagher D, Larson EL, Wang YHC, Richards B, Weng C, Hametz P, Begg MD, Chung WK, Boden-Albala B, Akabas SR (2010) Identifying interdisciplinary research priorities to prevent and treat pediatric obesity in New York City. Clin Transl Sci 3:172177. https://doi.org/10.1111/j.1752-8062.2010.00210.x

Ghaffar A (2009) Setting research priorities by applying the combined approach matrix. The Indian Journal Of Medical Research 129:368-375

Graham L, Illingworth BJG, Showell M, Vercoe M, Crosbie EJ, Gingel LJ, Farguhar CM, Horne AW, Prior M, Stephenson JM, Magee LA, Duffy JMN, Crosbie (2020) Research priority setting in women's health: a systematic review. BJOG 127:694700. https://doi.org/10.1111/1471-0528.16150

Halvatsiotis P, Kotanidou A, Tzannis K, Jahaj E, Magira E, Theodorakopoulou M, Konstandopoulou G, Gkeka E, Pourzitaki C, Kapravelos N, Papoti S, Sileli M, Gogos C, Velissaris D, Markou N, Stefanatou E, Vlachogianni G, Aimoniotou E, Komnos A, Zafeiridis T, Koulouvaris P, Armaganidis A, Bamias A, Dimopoulos G (2020) Demographic and clinical features of critically ill patients with COVID-19 in Greece: The burden of diabetes and obesity. Diabetes Res Clin Pract 166:108331. https://doi.org/10.1016/j.diabres.2020.108331

Hennessy M, Byrne M, Laws R, Mc Sharry J, O'malley G, Heary C (2018) Childhood obesity prevention: priority areas for future research and barriers and facilitators to knowledge translation, coproduced using the nominal group technique. Transl Behav Med 9(4):759-767. https://doi.org/10.1093/tbm/iby074

Hill B, Skouteris H, Boyle JA, Bailey C, Walker R, Thangaratinam S, Sundseth H, Stephenson J, Steegers E, Redman LM, Montanaro C, Lim S, Jorgensen L, Jack B, Borges ALV, Bergmeier HJ, Baxter JAB, Harrison CL, Teede HJ (2020) Health in preconception, pregnancy and postpartum global alliance: international network pregnancy priorities for the prevention of maternal obesity and related pregnancy and long-term complications. J Clin Med 9(3):822. https://doi.org/10.3390/jcm9030822

Hill B, Skouteris H, Teede HJ, Bailey C, Baxter JAB, BergmeierHJ BALV, Harrison CL, Jack B, Jorgensen L, Lim S, Montanaro C, Redman L, Steegers E, Stephenson J, Sundseth H, Thangaratinam S, Walker R, Boyle JA (2019) Health in preconception, pregnancy and postpartum global alliance: international network preconception research priorities for the prevention of maternal obesity and related pregnancy and long-term complications. J Clin Med 8(12):2119. https://doi.org/10.3390/jcm81 22119

Iqbal H, West J, Haith-Cooper M, Mceachan RRC (2021) A systematic review to identify research priority setting in Black and minority ethnic health and evaluate their processes. Plos One 16:e0251685. https://doi.org/10.1371/journal.pone.0251685

James Lind Alliance (JLA) (2020) JLA guidebook. Available online at: https://www.jla.nihr.ac.uk/jla-guidebook/chapter-7/colla ting-and-scoring-interim-priorities.html Accessed 23 Nov 2020

Mador RL, Kornas K, Simard A, Haroun V (2016) Using the Nine Common Themes of Good Practice checklist as a tool for evaluating the research priority setting process of a provincial research and program evaluation program. Health Res Policy Syst 14:1-9. https://doi.org/10.1186/s12961-016-0092-5

Mama SK, Soltero EG, Ledoux TA, Gallagher MR, Lee RE (2014) Solving the obesity epidemic: voices from the community. Nurs Inq 21:192-201. https://doi.org/10.1111/nin.12054

Manikam L, Shah R, Reed K, Santini G, Lakhanpaul M (2017) Using a co-production prioritization exercise involving South Asian 
children, young people and their families to identify health priorities requiring further research and public awareness. Health Expect 20:852-861. https://doi.org/10.1111/hex.12524

McGregor S, Henderson KJ, Kaldor JM (2014) How are health research priorities set in low and middle income countries? A systematic review of published reports. Plos One 9:e108787. https://doi.org/10.1371/journal.pone.0108787

McKinnon RA, Orleans CT, Kumanyika SK, Haire-Joshu D, KrebsSmith SM, Finkelstein EA, Brownell KD, Thompson JW, Ballard-Barbash R, Mckinnon RA, Orleans CT, Kumanyika SK, Haire-Joshu D, Krebs-Smith SM, Finkelstein EA, Brownell KD, Thompson JW, Ballard-Barbash R (2009) Considerations for an obesity policy research agenda. Am J Prev Med 36:351-357. https://doi.org/10.1016/j.amepre.2008.11.017

McPherson AC, Ball GDC, Maltais DB, Swift JA, Cairney J, Knibbe TJ, Krog K (2016) A call to action: Setting the research agenda for addressing obesity and weight-related topics in children with physical disabilities. Child Obes 12:59-69. https://doi.org/10. 1089/chi.2015.0119

Nasser M, Welch V, Tugwell P, Ueffing E, Doyle J, Waters E (2013) Ensuring relevance for Cochrane reviews: evaluating processes and methods for prioritizing topics for Cochrane reviews. J Clin Epidemiol 66:474-482. https://doi.org/10.1016/j.jclinepi.2012. 01.001

NHS Digital (2020) Statistics on obesity, physcial activity and diet, England. Available online at: https://digital.nhs.uk/data-andinformation/publications/statistical/statistics-on-obesity-physi cal-activity-and-diet/england-2020. Accessed 16 Nov 2020

Owens C, Ley A, Aitken P (2008) Do different stakeholder groups share mental health research priorities? A four-arm Delphi study. Health Expect 11:418-431. https://doi.org/10.1111/j. 1369-7625.2008.00492.x

Public Health England (2020) Excess weight and COVID-19: insights from new evidence. Public Health England. Available online at: https://assets.publishing.service.gov.uk/gover nment/uploads/system/uploads/attachment_data/file/907966/ PHE_insight_Excess_weight_and_COVID-19_FINAL.pdf. Accessed 17 Nov 2020

Pollack LM, Wang M, Leung MYM, Colditz G, Herrick C, Chang SH (2020) Obesity-related multimorbidity and risk of cardiovascular disease in the middle-aged population in the United States. Prev Med 139:106225. https://doi.org/10.1016/j.ypmed. 2020.106225

Ramirez AG, Chalela P, Gallion KJ, Green LW, Ottoson J (2011) Salud America! Developing a national Latino childhood obesity research agenda. Health Educ Behav 38:251-260. https://doi. org/10.1177/1090198110372333

Reveiz L, Elias V, Terry RF, Alger J, Becerra-Posada F (2013) Comparison of national health research priority-setting methods and characteristics in Latin America and the Caribbean, 2002-2012. Revista Panamericana de Salud Publica 34:1-13

Rudan I (2016) Setting health research priorities using the CHNRI method: IV. Key conceptual advances. J Global Health 6:010501-010501

Rudan I, Kapiriri L, Tomlinson M, Balliet M, Cohen B, Chopra M (2010) Evidence-based priority setting for health care and research: tools to support policy in maternal, neonatal, and child health in Africa. Plos Med 7:e1000308. https://doi.org/10.1371/ journal.pmed. 1000308

Shamseer L, Moher D, Clarke M, Ghersi D, Liberati A, Petticrew M, Shekelle P, Stewart LA (2015) Preferred reporting items for systematic review and meta-analysis protocols (PRISMA-P) elaboration and explanation. BMJ (Clinical research ed.) 350:g7647. https://doi.org/10.1136/bmj.g7647

Sibbald SL, Singer PA, Upshur R, Martin DK (2009) Priority setting: what constitutes success? A conceptual framework for successful priority setting. BMC Health Serv Res 9:43

Staniszewska S, Brett J, Simera I, Seers K, Mockford C, Goodlad S, Altman DG, Moher D, Barber R, Denegri S, Entwistle A, Littlejohns P, Morris C, Suleman R, Thomas V, Tysall C (2017) GRIPP2 reporting checklists: tools to improve reporting of patient and public involvement in research. BMJ 358:j3453. https://doi.org/10.1136/bmj.j3453

Tallon D, Chard J, Dieppe P (2000) Relation between agendas of the research community and the research consumer. Lancet 355:2037-2040. https://doi.org/10.1016/S0140-6736(00) 02351-5

Taylor RW, Robinson A, Espinel PT, Baur LA, Wake M, Sabin MA (2013) Research priorities in 2012 for the effective management of childhood obesity. Clin Obes 3:3-6. https://doi.org/10.1111/ cob.12014

Terry RF, Charles E, Purdy B, Sanford A (2018) An analysis of research priority-setting at the World Health Organization - how mapping to a standard template allows for comparison between research priority-setting approaches. Health Res Policy Syst 16:116. https://doi.org/10.1111/cob.12014

Tong A, Chando S, Crowe S, Manns B, Winkelmayer WC, Hemmelgarn B, Craig JC (2015) Research priority setting in kidney disease: a systematic review. Am J Kidney Dis 65:674-683

Tong A, Synnot A, Crowe S, Hill S, Matus A, Scholes-Robertson N, Oliver S, Cowan K, Nasser M, Bhaumik S, Gutman T, Baumgart A, Craig JC (2019) Reporting guideline for priority setting of health research (REPRISE). BMC Med Res Methodol 19:1-11. https://doi.org/10.1186/s12874-019-0889-3

Viergever and Roderik (2010) Health research prioritization at WHO - an overview of methodology and high level analysis of WHO led health research priority setting exercises pp 2-30. https:// www.ip-watch.org

Viergever RF, Olifson S, Ghaffar A, Terry RF (2010) A checklist for health research priority setting: nine common themes of good practice. Health Res Policy Syst 8:36

Voigt I, Wrede J, Diederichs-Egidi H, Dierks ML, Junius-Walker U (2010) Priority setting in general practice: Do health priorities of older patients differ from treatment priorities of their physicians. Croatian Med J 51:483-492. https://doi.org/10.3325/cmj. 2010.51.483

Ward DS, Vaughn A, Story M (2013) Expert and stakeholder consensus on priorities for obesity prevention research in early care and education settings. Child Obes 9:116-124. https://doi.org/ 10.1089/chi.2013.9204

World Health Organization (WHO) (2017) Obesity and overweight. Available online at: http://www.who.int/mediacentre/factsheets/ fs311/en. Accessed 20 Nov 2020

Yoshida S (2016) Approaches, tools and methods used for setting priorities in health research in the 21st century. J Global Health 6:010507-010507

Publisher's note Springer Nature remains neutral with regard to jurisdictional claims in published maps and institutional affiliations. 